\title{
Allowance for Sequence of Mass Concrete Dam Erection on Soils During its Stress-strain Analysis
}

\author{
Igor Konstantinov ${ }^{1}$, Sergey Kuzmin ${ }^{1}$, Alexey Savchenko ${ }^{1}$, Pavel Boychenko ${ }^{1, *}$ and Diana \\ Nagornya ${ }^{1}$ \\ ${ }^{1}$ St.-Petersburg State Polytechnical University, Politechnicheskaya St., 29, St. Petersburg, 195251, \\ Russian Federation
}

\begin{abstract}
The following are the research results made both at lengthwise and width directions with and without accounting sequence of a section erection. Calculations were performed in the maths laboratory of «B.E. Vedeneev VNIIG» with software assistance. The main aim of the study is to search for the optimal stress-strain behavior of the dam in terms of forming minimal tension in concrete.
\end{abstract}

\section{Introduction}

While designing such critical structures as concrete dams, it is very important to analyze their stress-strain behavior [1-6]. Therefore a selection of a relevant structural design of the dam is also of great importance.

In operative design and construction specifications [7] when choosing structural design of a concrete dam including ones on soils, it is recommended to take into account the sequence of its erection and loads. Rational erection sequence enables better formation of stress-strain behavior in the dam. While designing mass concrete dams on soils (using specific conditions), a choice of an appropriate erection sequence can be done only when a full picture of dam stress-strain behavior at various schemes of installation is well identified.

Nowadays a stress-strain behavior of mass concrete dams on soils at various stages of its erection and loads is quite understudied. The majority of works, concerning this issue were published at the time when calculation methods as well as abilities of PC remarkably limited possibilities of problem solving even in the context of plane elasticity. Today we have more powerful PCs. The finite element method is now widely used for practical design calculations. There is a number of software products (based on finite element method) for solving plane and three-dimensional elasticity used by various scientific institutes and design organizations. These factors remarkably enhances studies in stressstrain behavior of mass concrete dams on soils with consideration of the dams erection sequence and their interaction with foundations. This question was partly considered in the work [8], where in the context of plane elasticity several loading schemes of mass concrete

\footnotetext{
${ }^{*}$ Corresponding author: boychenko pavel@icloud.com
} 
dam (when operated at lengthwise direction) were analyzed. However, the dam erection sequence was not considered in that case.

A section of a dam (transversal and longitudinal sections depicted on Figure1) under inquiry is a monolithic spatial structure with (Figures 1b-c) piers, base slab and crown of inlet on which valve is located. Young's modulus, unit weight, Poisson's ratio of the dam's material are as follows: $\mathrm{E}_{\delta}=2 \cdot 104 \mathrm{MPa}, \gamma_{\delta}=24 \mathrm{kN} / \mathrm{m} 3, v_{\delta}=0.17$.

When the valve is closed, basic static loads are following: the dead load of the section, water pressure on both downstream and upstream sides and the counterpressure through the foot of the dam. It is expected that the section bears on foundation with deformation modulus E0 $=20 \mathrm{MPa}$ (fine sand) [11]. Poisson's ratio of $v 0=0.25$ taken in this study was a quite different that the recommended one [11] $v 0=0.3$. However, this mismatching slightly influenced stress state and distorted the performance. Practical use of available software for such complicated three-dimensional structure as section of concrete dam on soils is a very difficult task due to the unavailability of automatic boundaries division of the area. That is the reason why the problem of stressed three-dimensional section was approximately solved by analyzing some plane sections. The section included inlet and base slab (Figures 1a-b) was considered for examining stress state in longitudinal section. Furthermore, the task of plane strain of the body interacting with foundation was solved. That method didn't take account of piers influence on stresses in the body.

а)

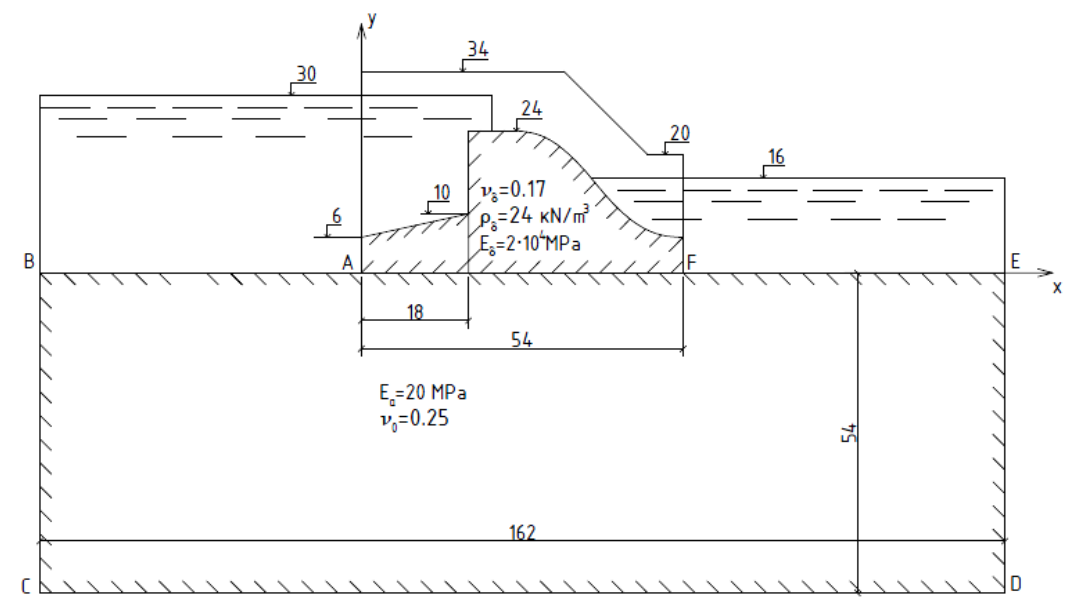

b)
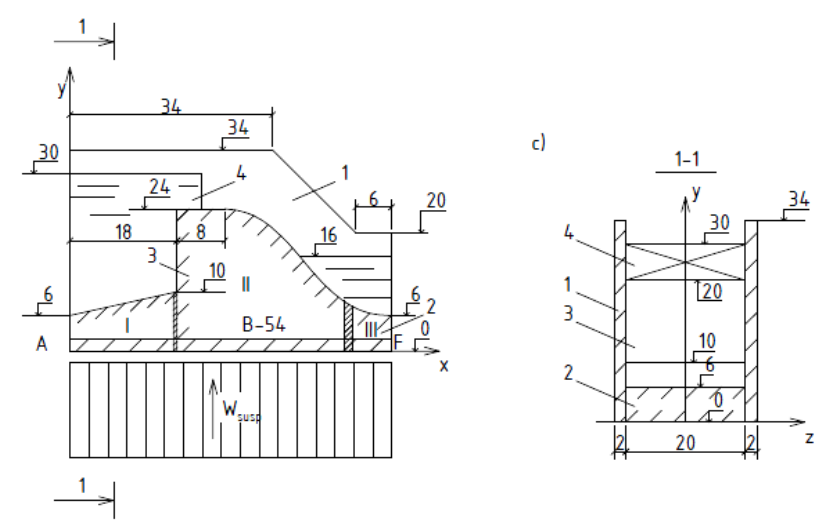

Fig. 1. Structural design: a) design section of the dam and its base zone; b) longitudinal design section of the dam; c) transversal design section of the dam 
Stress condition in sections of the body near piers was different from the one found along the centerline. That is why reduced flat stress problem was used in order to roughly take account of piers influence. For this purpose, piers were calculated with density reduced proportionally and following modulus of elasticity: $\rho_{\mathrm{pr}}=\rho_{\delta} \cdot \mathrm{t} / \mathrm{L} ; \mathrm{E}_{\mathrm{pr}}=\mathrm{E}_{\delta} \cdot \mathrm{t} / \mathrm{L}$

where $\mathrm{t}$ - width of two half-piers in a section, $\mathrm{L}$ - overall section width.

After some calculations, tension in pier were increased to $\sigma_{\delta}=\sigma \cdot \sigma_{\mathrm{pr}} \cdot \mathrm{L} / \mathrm{t}$. When calculating, as for account of piers, plane strain problem of body interacting with foundation was solved. Allowance for foundation was made according to [12]. Dimensions of foundation were chosen as follows: $\mathrm{AB}=\mathrm{BC}=\mathrm{DE}=\mathrm{EF}=\mathrm{B}$,

where $\mathrm{B}-$ longitudinal length of a foot of a dam.

Stresses on BCDE line were calculated according to $\sigma_{\mathrm{y}}$ and $\tau_{\mathrm{xy}}$ linearly distributed along the foot of a dam. They were taken based on eccentric compression formulae. Consequently, self-equilibrated forces on CD were not considered. However, that is quite legitimate according to Saint-Venant's Principle.

Calculations were performed with an allowance for two schemes of erection:

1. The dam was believed to be erected by layers. Layer thickness was taken according to recommendations [13]. Hydrostatical pressure and backpressure along the foot of a dam were exerted to the section erected by that time.

2. Dam body was erected layer-by-layer by means of three different parts (Figure 1b, pt. I-III). Only when the parts were erected to the projected height, joints of base slab were concreted. Hydrostatical pressure and backpressure were exerted to the monolithic body along its foot.

Assuming that the dead weight of the structure and hydrostatical pressure exerted to 'momentary' erected structure (Figure 1b), calculations were made to associate longitudinally stress condition of the section with allowance for sequence of structure erection.

A rapid estimate of section's stress condition transversally (crosswise of water current) was considered in conditions of plane strain in section I-I (Figures 1a,c). The following are two options of erection:

1. Base slab and piers were erected separately, then joints were concreted and finally hydrostatical pressure was exerted.

2. Base slab and piers were erected together. Loading was exerted along edges of the slab. Joints between sections were conditionally extended to foundation area. Influence between adjoining sections (same width as a layer) equals to a dam section width (Figure 1c).

Results of calculation are given below on Figures 2-4 in the form of normal stress distribution diagrams $\sigma_{\mathrm{x}}$ in vertical direction. Analyzing them, we can estimate occurrence of tensile zones of concrete.

1. Figure 2a depicts diagram $\sigma_{\mathrm{x}}$ (stress distribution in vertical sections of solid part of a dam section). The diagrams marked with ' 1 ' were obtained assuming that the only dead weight was applied (without contribution of piers) and that the structure was momentary erected. The diagrams marked with '2'stand for simultaneous actions of dead weight, hydrostatical pressure and backpressure along the foot of a dam. Diagrams 1 and 2 comparison demonstrates that one load from dead weight leads to greater tension $\sigma_{x}$.

The diagrams marked with ' 3 ' stand for solution of reduced flat stress problem using basic loads. Piers' effect on stresses in the body were approximately included. A section, as in earlier cases, was considered to be exerted when all loads could be applied. As we can see, allowing for piers' effect massif became stiffer and there were no tensile zones at all. Figure $2 \mathrm{~b}$ depicts diagrams $\sigma_{\mathrm{x}}$ (sections 0.5 meters apart from section's base). Let us make notice of diagram 2 and 3. Both of them are different from those introduced in the work [9]. There we did not take into account a backpressure along the foot of the dam. 


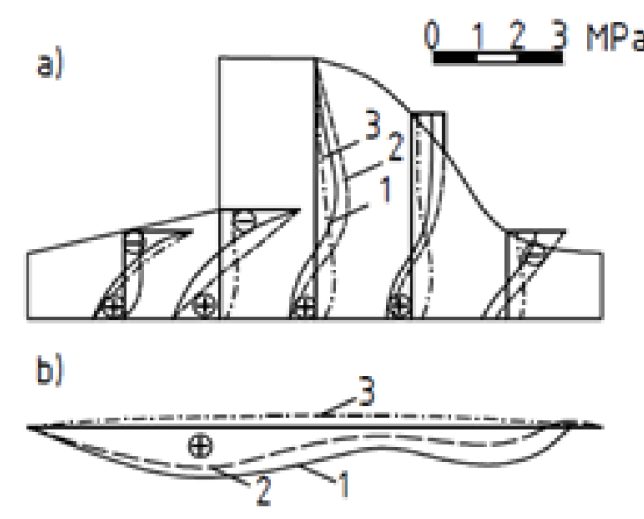

Fig. 2. Diagrams of direct stresses $\sigma_{x}:$ a) $\sigma_{x}$ across longitudinal sections of the section; b) $\sigma_{x} 0.5$ meters apart from the foot. $1-\sigma_{\mathrm{x}}$ when momentary erected and exerted by dead weight without piers' effect; $2-\sigma_{x}$ when momentary erected and exerted by basic loads without piers' effect; $3-\sigma_{x}$ when momentary erected and exerted by basic loads with piers' effect

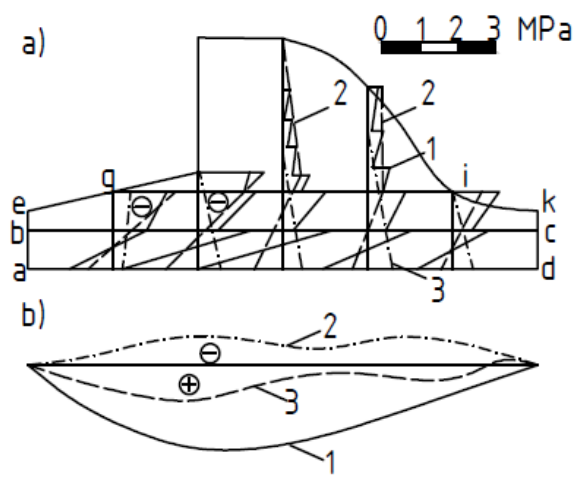

Fig. 3. Diagrams of direct stresses $\sigma_{x}$ with consideration of sequence of erection: a) $\sigma_{x}$ across longitudinal sections of the section; b) $\sigma_{\mathrm{x}} 0.5$ meters apart from the foot. $1-\sigma_{\mathrm{x}}$ when erected layer-bylayer; $2-\sigma_{x}$ when erected layer-by-layer with casting joints in the base slab; $3-\sigma_{x}$ when momentary erected

Fig. 3a-b depicts a match of diagrams $\sigma_{\mathrm{x}}$ (longitudinal sections 0.5 meters apart from the foot; the option without piers' effect and with layer-by-layer erection). It's assumed, that layers were erected 'momentary'. First layer maximum thickness h1 $=4.5 \mathrm{~m}$, [13]. The next layer $\mathrm{h} 2=3 \mathrm{~m}$ was placed after the solidification of concrete of the first one. Furthermore, tension $\sigma_{\mathrm{x}}$ appeared to be a result of bending in abcd layer. Relevant diagrams are approximately linear due to ration of $\mathrm{h} 1$ to $\mathrm{B}$. When the second layer with adjustable height gained its strength, the third layer with $\mathrm{h} 3=3 \mathrm{~m}$ was casted. When the massif had been erected, a hydrostatical pressure and a backpressure were exerted. Final and conclusive lattice diagrams $\sigma_{\mathrm{x}}$ resulted from the same loads, but without consideration of sequence of erection (Figure 2a-b). On the contrary, the option with layer-by-layer erection and with casting joints led to diagrams $\sigma_{\mathrm{x}}$ (dot-dash curve marked with '2', Figure 3a-b).

As it was discussed above, concreting in lifts (layer-by-layer) with casting joints helped to avoid lengthwise tension $\sigma_{\mathrm{x}}$ in the whole section even without piers' effect. 
However, concreting in lifts without vertical joints led to more complicated stress distribution. Furthermore, the smaller the first layer was, the greater stresses $\sigma_{\mathrm{x}}$ were registered while concreting the next layer. Consequently, a thickness of the first layer should be as great as possible. The dead weight of the first one didn't set up any stresses $\sigma_{\mathrm{x}}$ across the section. That happened because of strain (due to base slenderness), which took place when the layer had not solidified yet.

First superjacent layers set up the major part of stresses $\sigma_{x}$ in the first layer because accumulative section wasn't very thick. Calculation of following layers illustrated interesting constraint. Right after the first layer was loaded by the second one, $36 \%$ of maximum tensile stresses $\sigma_{\mathrm{x}}$ developed across the lower part of the first one. When the first layer was loaded by the third one $-64 \%$ were registered etc. The higher the loading layer was, the less it affected the developing of tensile stresses because the thickness of accumulative section was always increasing.

In the process of increasing loads and stresses $\sigma_{x}$ the neutral axis position was within the first layer during the whole process of erection. The tensile stresses obtained, were 2-3 times greater than stresses had come from the 'momentary' scheme. Moreover, maximum tensile stresses $\sigma_{\mathrm{x}}$ developed across the middle vertical crosses of the foot. On the contrary, when we had 'momentary' erection maximum stresses developed in the cross aligned with dam crown of upstream face.

3. Figure $4 \mathrm{a}-\mathrm{b}$ depicts comparison of diagrams $\sigma_{\mathrm{z}}$ across vertical sections through upper and lower fibers of the base slab's section in a lateral direction.

The diagrams $\sigma_{z}$ marked with ' 1 ' were obtained from the base slab and piers separate erection (the 1st scheme of erection) from all basic type of loads. The diagrams $\sigma_{z}$ marked with ' 2 ' were obtained from layer-by-layer erection of the section as a single whole (the 2nd scheme of erection) without consideration of hydrostatical pressure.

The first scheme of erection diagrams displays that maximum tensile stresses $\sigma_{z}$ in the middle of the foot took place at the outset of erection. Tensile stresses on the periphery of the section took place only after hydrostatical pressure was exerted.

When analyzing diagrams obtained from the second scheme of erection (with piers' effect), it turned out that during erection tensile stresses $\sigma_{z}$ developed across upper layers of the base slab. Furthermore, compression stresses $\sigma_{\mathrm{z}}$ across lower layers disappeared. By these means, the most dangerous stress state occurs during construction period.

\section{Summary}

The carried-out calculations allow to approve the following: significant tensile stresses took place generally by means of surcharge weights of piers. That is the reason of essential base slab reinforcement of both upper and lower parts of it. Calculations and further analysis demonstrates that during the construction period a dam body should be erected detached from piers with casting joints. Those joints should be concreted at the end of the section erection. 


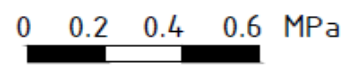

a)

b)
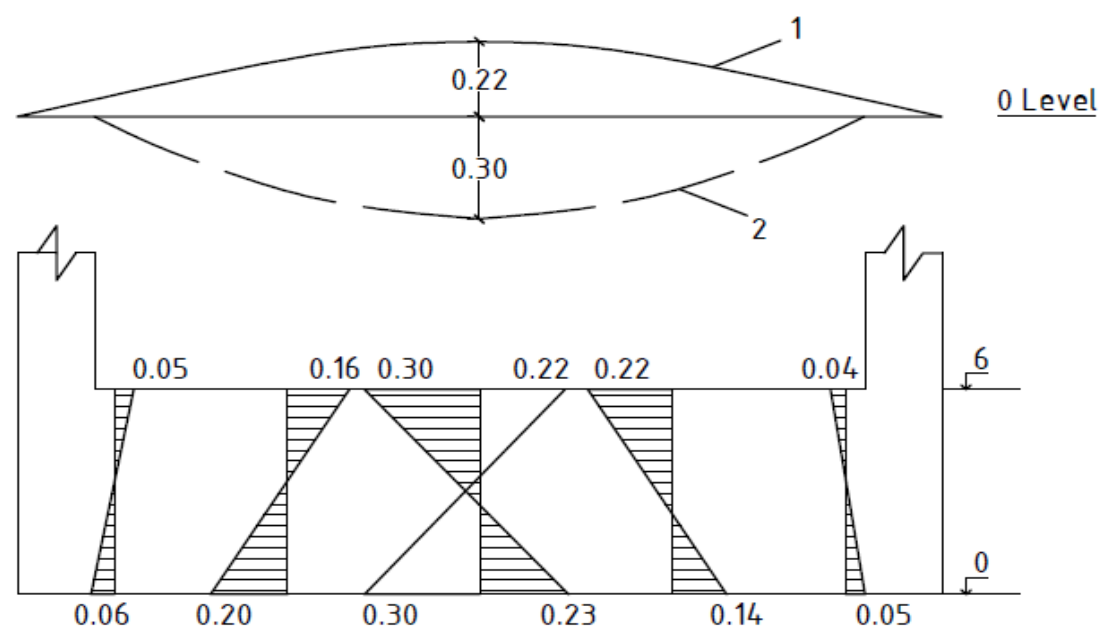

c)

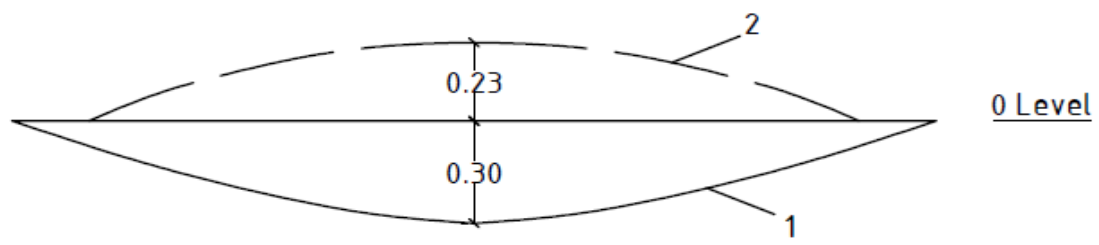

Fig. 4. Diagrams of direct stresses $\sigma_{\mathrm{z}}$ (section I-I): a) $\sigma_{\mathrm{z}}$ across vertical areas through upper edge of the base slab; b) $\sigma_{z}$ across vertical sections; c) $\sigma_{z}$ across vertical areas nearby dam's foot. 1 - the base slab and piers separate erection; 2- layer-by-layer erection of the section as a single whole

\section{References}

1. Bukhartsev V.N., Petrichenko M.R., Power Techology and Engineering, 46(3), 185-189 (2012)

2. Bukhartsev V.N., Petrichenko M.R., Power Techology and Engineering, 46(3), 1-3 (2012)

3. Kolosova G.S., Lalin V.V., Kolosova A.V., Magazine of civil engineering, 5, 76-85 (2013)

4. Benin A.V., Semenov A.S., Semenov S.G., Advanced Materials Research, 831, 364-369 (2014)

5. Kitaeva D.A., Rudaev Y.I., Ordobaev B.S., Abdykeeva S.S. Applied Mechanics and Materials, 725-726, 623-628 (2014)

6. Lalin V.V., Savchenko A.V., Zdanchuk E.V., Yavarov A.V., Belyaev D.I., Construction of unique building and structures, 7, 30-37. (2013)

7. Code Design 40.13330.2012 Concrete and reinforced concrete dams. (Moscow, Minregion Russia, 2012)

8. Dyatlovitskiy L.I. Napryazheniya $v$ gravitatsionnikh plotinakh na neskalnikh osnovaniyakh [Stresses in gravity dams on the not rocky grounds] (AN YSSR, 1959) 
9. Konstantinov I.A., Kuzmin S.A. Issledovanie napryazhennogo sostoyaniya betonnoy vodoslivnoy plotiny na neskalnikh gruntakh metodom konechnykh elementov [Investigation of the stress state of the concrete spillway dam on the not rocky grounds with finite element method]. (col.book Altay Polytechnic University, 1985)

10. Ymanskiy A.A. Spravochnik proektirovshika [Designer's reference book]. (vol.2 Moscow, 1973)

11. Efimov YU.N., Kolosova G.S., Konstantinov I.A., Sapozhnikov L.B. Ychet podatlivosti osnovaniya pri staticheskom raschete plotin metodom konecnykh elementov [Accounting for compliance of foundation in static analysis of dams with finite element method]. (B.E. Vedeneev VNIIG, 1973)

12. Grishin M.M. Gidrotehnicheskie sooruzheniya [Hydrotechnical constructions] (Vyssh.shk, 1979)

13. Teleshev V.I. Konstruktivno-tekhnologicheskie meropriyatiya po obespecheniyu treshinostoykosti i monolitnosti massivnyh betonnikh gidrotehnicheskikh sooruzheniy [Design and technological measures to ensure the fracture toughness and solidity of massive concrete hydraulic structures] (LPI, 1983)

14. Katzenbach R., Werner A., Kempfert H.-G., Savidis S., Steffens K., Wesemüller H. Darmstadt Geotechnics, 11, 109-12. (2003)

15. L. Svatovskaya, A. Sychova, M. Sychov, V. Okrepilov, MATEC Web of Conferences, 53, Article Number 01023 (2016)

16. Argal É., Korolev V., Kudrin K., Ashikhmen V. Power Technology and Engineering (formerly Hydrotechnical Construction), 43(6), 337-344 (2009)

17. Mirzabozorg H., Ghaemian M., Noorzad A., Abbasi Zoghi M. International Journal of Earthquake Engineering and Engineering Seismology (EEE), 3, 52-60 (2007)

18. Mirzabozorg H., Khaloo A.R., Ghaemian M., Jalalzadeh B. International Journal of Earthquake Engineering and Engineering Seismology (EEE), 2, 48-57 (2007)

19. Brandão J.L.B. Water Resources Management, 24(12), 3101-3114 (2010)

20. Kurzin V. B., Seleznev V. S., Journal of Applied Mechanics and Technical Physics, 51(4), 590-597 (2010) 